Gut, 1982, 23, 739-743

\title{
Effects of morphine on human pancreatic secretion: studies on pure pancreatic juice
}

\author{
L GULLO,* PATRIZIA PRIORI, P L COSTA, D GARCEA, \\ F BALDONI, G MATTIOLI, and G LABO
}

From the Pancreatic Disease Unit, Institute of Medicine and Gastroenterology, University of Bologna, St Orsola Hospital, Bologna, and Division of Surgery, Maggiore Hospital, Bologna, Italy

SUMMARY Data concerning the effects of morphine on human pancreatic secretion are fragmentary and inconclusive. In the present study, we evaluated the effects of morphine on pure pancreatic secretion in nine subjects with external transduodenal drainage of the main pancreatic duct performed after biliary tract surgery. Intravenous infusion of a small dose of morphine, 40 $\mu \mathrm{g} / \mathrm{kg} / \mathrm{h}$, during pancreatic stimulation with secretin and cholecystokinin, caused a significant increase in volume, bicarbonate, and calcium secretion, and a significant decrease in protein secretion. The stimulatory effect on water and electrolyte secretion was rapid and much more pronounced, reaching about $45-50 \%$ of the control levels, whereas the inhibition of protein output was slightly delayed and of lesser magnitude, reaching about 20-25\% of the control values. Both effects were long-lasting. The addition of naloxone, a potent opiate antagonist, prevented in part the effects of morphine on pancreatic secretion, suggesting that specific opiate receptors might be involved in these effects.

Despite the extensive literature on the influences of morphine on the gastrointestinal tract, very little is known about the effects of this drug on pancreatic exocrine secretion of man. In textbooks of pharmacology ${ }^{12}$ it is stated that morphine inhibits human pancreatic secretion but there are no detailed studies proving that such an effect occurs in man. The present study was therefore designed to examine the effects of morphine on human pancreatic secretion. These effects were evaluated directly on pure pancreatic juice collected by external transduodenal drainage of the main pancreatic duct.

\section{Methods}

SUBJECTS

Nine subjects (five men and four women) with no clinical history or biochemical signs of pancreatic disease were studied. They ranged in age from 41 to 72 years (mean 58 years). Their weights ranged from

\footnotetext{
* Address for correspondence: Dr Lucio Gullo, Istituto di Clinica Medica e Gastroenterologia, Ospedale S. Orsola, Via Massarenti, 940138 Bologna, Italy.

Received for publication 8 December 1981
}

45 to $68 \mathrm{~kg}$ (mean $57 \mathrm{~kg}$ ). Informed consent was obtained from each subject. The method for collecting pure pancreatic juice has been described in previous publications. ${ }^{34}$ The patients had transduodenal drainage of the main pancreatic duct performed after papillotomy and sphincteroplasty for common bile duct stones. ${ }^{5}$ The appearance of the pancreas at operation was normal in all patients. The drainage was not carried out specifically for the purpose of this study, but as a part of the therapeutic programme to prevent the formation of duodenal fistulae and postoperative acute pancreatitis. The polyethylene tubes used to drain pancreatic juice were inserted into Wirsung's canal to a depth of about $3-4 \mathrm{~cm}$, and were tied to the duodenal wall by a stitch of catgut. They were provided with several additional holes in the intraductal portion. Their diameter was accurately selected in each patient according to the calibre of the main pancreatic duct. After insertion of the tube into the duct of Wirsung, an intravenous injection of secretin, $0.5 \mathrm{CU} / \mathrm{kg}$, was carried out to confirm the efficacy of the drainage. There was no obvious leakage of pancreatic juice around the cannula after secretin administration. Studies were performed in the morning after an overnight fast, and were started at least five or six 
days after the operation. It has been shown that pancreatic secretion is depressed during the first two to three days after the operation and returns to normal thereafter. ${ }^{36}$ To obtain a steady state secretion, the pancreas was stimulated with a constant intravenous infusion of secretin, $0.5 \mathrm{CU} /$ $\mathrm{kg} / \mathrm{h}$, and cholecystokinin, $0.5 \mathrm{IDU} / \mathrm{kg} / \mathrm{h}$, dissolved in physiological saline. Both secretin and cholecystokinin were obtained from the GIH Laboratory, Karolinska Institute, Stockholm, Sweden. In order to avoid the entry of acid into the duodenum, gastric juice was continuously aspirated by a nasogastric tube positioned before each study. Pancreatic juice was collected in ice-chilled graduated tubes at 10 -minute intervals. Each patient underwent two tests in random order on two separate days. On one day, an intravenous infusion of morphine hydrochloride, $40 \mu \mathrm{g} / \mathrm{kg} / \mathrm{h}$, dissolved in $50 \mathrm{ml}$ saline, was started 60 minutes after the beginning of the secretin-cholecystokinin infusion and continued for 30 minutes. On the other day an intravenous infusion of physiological saline, $50 \mathrm{ml}$, was given instead of morphine. After stopping the morphine or saline infusion, the secretincholecystokinin infusion and pancreatic juice collection were continued for a further 60 minutes. In the last three patients studied, an additional test was carried out on a separate day. In this third test, naloxone (Narcan, Endo Laboratories, Inc., Garden City, NY), an opiate antagonist, was added at a dose of $20 \mu \mathrm{g} / \mathrm{kg} / \mathrm{h}$ to the intravenous infusion five minutes before and during morphine administration. The dose of morphine was based upon the studies of Konturek et $\mathrm{al}^{7}$ in dog. In these studies, this dose was the lowest dose that caused maximal inhibition of pancreatic secretion.

Each 10-minute sample of pancreatic juice was analysed for volume, bicarbonate, total protein as a measure of enzyme secretion, and calcium. Bicarbonate was determined by the method of Van Slyke and Neil, ${ }^{8}$ total protein by the absorbance at $280 \mathrm{~nm},{ }^{9}$ and calcium by atomic absorption spectrophotometer. There was no evidence of bile contamination in any of the samples.

Results are presented as mean values \pm SEM. Statistical significance was assessed by Student's $t$ test for paired differences.

\section{Results}

VOLUME AND BICARBONATE

Both in morphine and control studies, a very stable plateau of secretion was attained about 30 minutes after the beginning of secretin-cholecystokinin infusion. The administration of morphine caused in all subjects an increase in pancreatic volume flow and bicarbonate secretion (Fig. 1). The increase was statistically highly significant. The effect appeared rapidly and persisted for some time after the infusion of morphine was stopped. Compared with control values, the increase in bicarbonate output reached about $50 \%$.

\section{PROTEIN}

Unlike bicarbonate secretion, protein secretion was significantly reduced by morphine (Fig. 2). The drug produced in all subjects a marked reduction in protein concentration. Thus, even though the pancreatic volume flow was increased by morphine, the output of protein was significantly reduced. Compared with control values, protein output was reduced by about $20-25 \%$ by morphine. The inhibition of protein was apparent from the second 10-minute period of morphine infusion and lasted for the duration of the study. In the first 10-minute period of the 30-minute morphine infusion protein concentration did not change significantly, so protein output was transiently augmented.

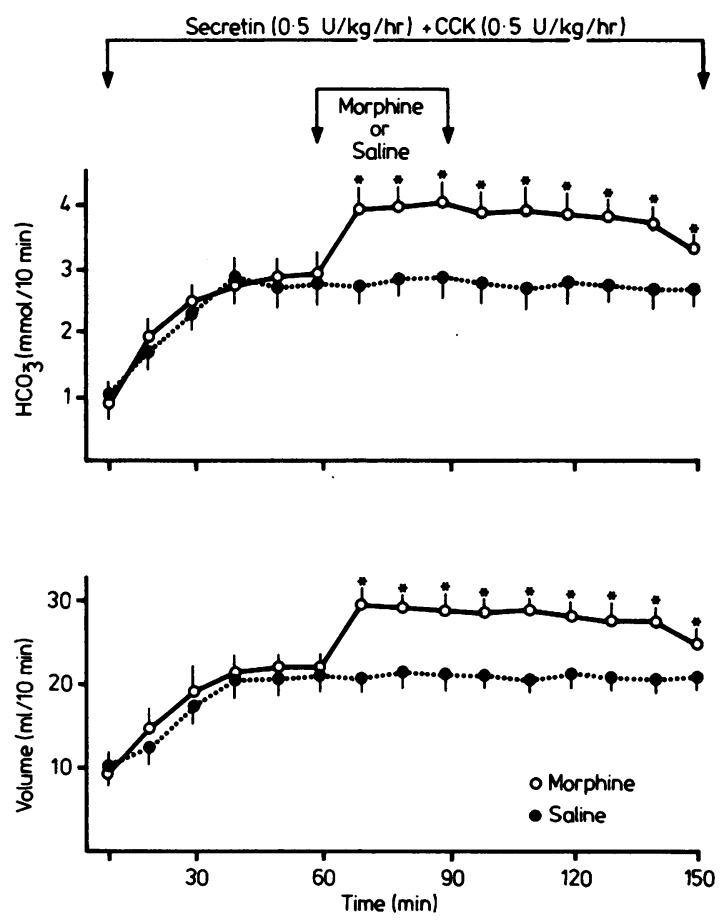

Fig. 1 Effects of morphine infused in a dose of $40 \mu \mathrm{g} / \mathrm{kg} / \mathrm{h}$ on secretin-cholecystokinin induced pancreatic juice flow and bicarbonate secretion in nine subjects. The values are means $\pm S E M$ of nine experiments. ${ }^{*} p<0.001$ when compared with control experiments. 

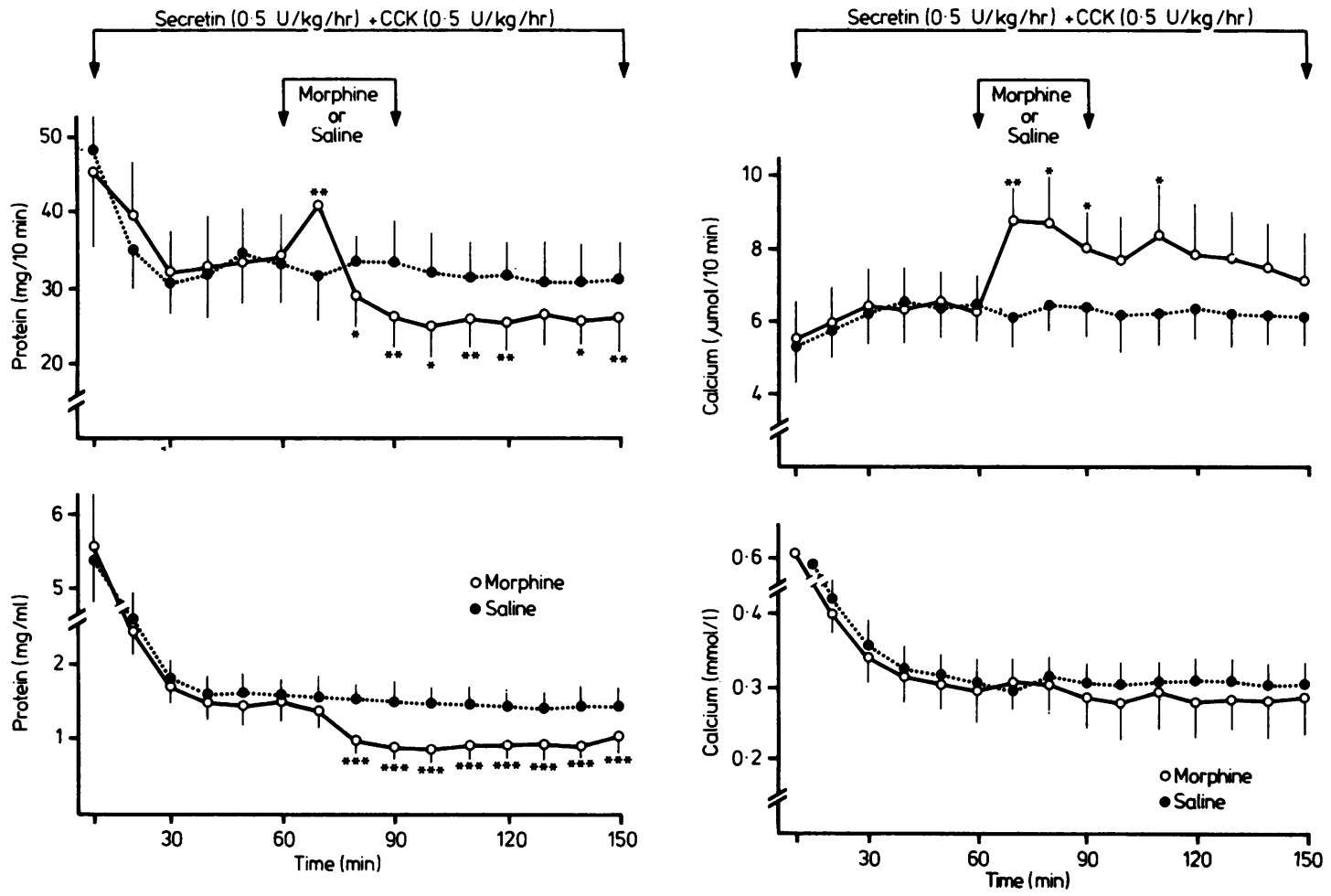

Fig. 2 Effects of morphine infused in a dose of $40 \mu \mathrm{g} / \mathrm{kg} / \mathrm{h}$ on secretin-cholecystokinin induced pancreatic protein secretion in nine subjects. The values are means $\pm S E M$ of nine experiments. ${ }^{*} p<0.05,{ }^{* *} p<0.025,{ }^{* * *} p<0.001$ when compared with control experiments.

\section{CALCIUM}

Calcium concentration was not significantly affected by morphine. In several patients there was a reduction in calcium concentration after morphine was given, but the decrease was very small. Calcium output increased rapidly after the beginning of morphine infusion and the effect persisted for the rest of the study (Fig. 3).

In studies in which the opiate antagonist naloxone was given with morphine, the effects of morphine were much less pronounced (Fig. 4).

Morphine in the small dose used in this investigation caused no symptoms in any of the patients.

\section{Discussion}

This study shows that morphine in a rather small dose is able to affect strongly human pancreatic secretion induced by secretin and cholecystokinin. Morphine caused two distinct and opposite effects

Fig. 3 Effects of morphine infused in a dose of $40 \mu \mathrm{g} / \mathrm{kg} / \mathrm{h}$ on secretin-cholecystokinin induced pancreatic calcium secretion in nine subjects. The values are means $\pm S E M$ of nine experiments. ${ }^{*} p<0.05,{ }^{* *} p<0.001$ when compared with control experiments.

on pancreatic secretion - namely, augmentation of water and electrolyte secretion and inhibition of protein secretion. The stimulatory effect on bicarbonate secretion was rapid and pronounced, reaching about $50 \%$ of the control levels, whereas the inhibitory effect on protein secretion was slightly delayed and of lesser magnitude, reaching about $20-25 \%$. Both effects were long-lasting, in keeping with the long duration of action of morphine. ${ }^{2}$ The data previously reported on the effects of morphine on human pancreatic secretion are fragmentary and inconclusive. Miller and Wiper ${ }^{10}$ reported that administration of morphine in a patient with an external pancreatic fistula reduced the volume flow from the fistula. Lagerlof ${ }^{11}$ compared duodenal secretion in three subjects after secretin with the secretion that occurred after secretin and morphine using duodenal intubation. He concluded that morphine inhibited secretion of pancreatic enzymes and decreased the delivery of bile and pancreatic 

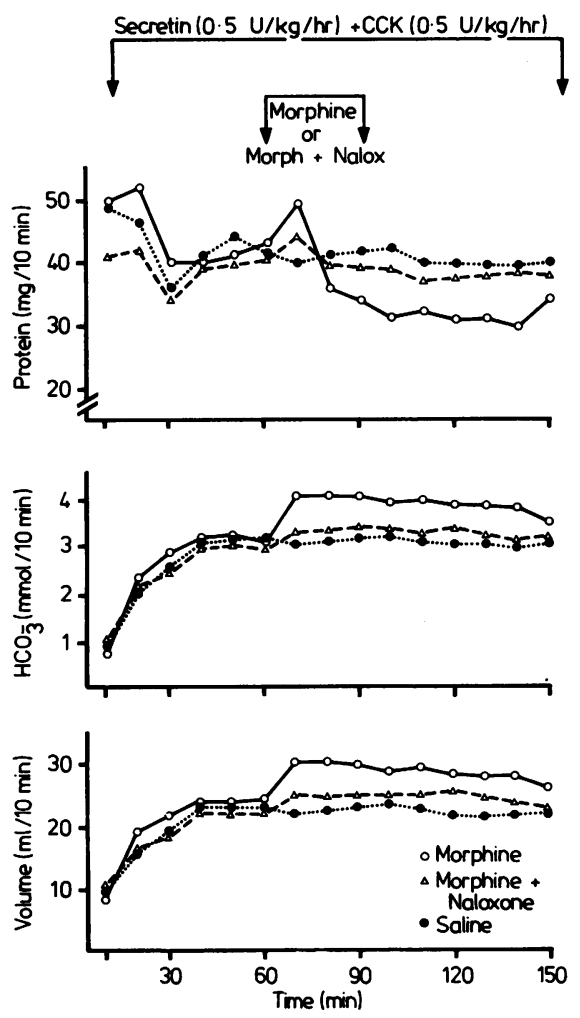

Fig. 4 Effects of morphine $(40 \mu \mathrm{g} / \mathrm{kg} / \mathrm{h})$ or morphine plus naloxone $(20 \mu \mathrm{g} / \mathrm{kg} / \mathrm{h})$ on secretin-cholecystokinin induced volume, bicarbonate, and protein secretion in three subjects The values are means of three experiments.

juice to the duodenum because of contraction of the sphincter of Oddi caused by the drug. To our knowledge, no further studies have examined the effects of morphine on human pancreatic secretion. In a recent study in dog, Konturek $e t a l^{7}$ found that morphine inhibits both pancreatic bicarbonate and protein secretion induced by endogenous and exogenous hormonal stimulation. This difference from our findings in man concerning the effect of morphine on bicarbonate secretion might be explained by species difference.

The mechanism whereby morphine exerts its effects on human pancreatic secretion is unknown. The rapid appearance of the increase in volume and bicarbonate secretion suggests that morphine may act directly on pancreatic secretory cells to stimulate water and bicarbonate secretion and augment the effect of secretin. The finding that naloxone, a potent opiate antagonist, prevents in part the augmenting effect of morphine on bicarbonate secretion suggests that this effect might be mediated in part by specific receptors for opiates. A similar conclusion has been reached by Konturek et al ${ }^{7}$ with regard to the effects of morphine on canine pancreatic secretion. The opiate receptors could be localised in the pancreatic secretory cells, but our study does not provide direct evidence for this assumption. Concerning the inhibitory effect on protein secretion, it is also possible that morphine acts directly on pancreatic acinar cells to inhibit protein secretion, perhaps by interfering with cholecystokinin. Moreover, as morphine is known to inhibit the release of acetylcholine from cholinergic nerve endings, ${ }^{12}{ }^{13}$. it is likely that the inhibition of protein secretion could be attributed, at least in part, to the removal of the cholinergic background involved in the action of cholecystokinin on the pancreatic acinar cells. ${ }^{14}$ The inhibitory effect on protein secretion was partly prevented by naloxone, suggesting involvement of specific opiate receptors.

Alternatively, the effects of morphine on pancreatic secretion might be mediated by actions of the drug on the brain. The observation that morphine administered in the systemic circulation does not readily cross the blood-brain barrier, however, ${ }^{15}$ makes it unlikely that a central nervous mechanism is involved in the effects seen in our study, and suggests that when the drug is given intravenously it acts peripherally.

It has been found that administration of morphine causes the release or suppression of several hormones, including prolactin and pancreatic polypeptide in man, ${ }^{16}{ }^{17}$ and somatostatin, glucagon, and insulin in dog. ${ }^{18}$ It is not possible, however, to determine if any of these hormones were involved in the effects of morphine on pancreatic secretion seen in the present study.

Of particular interest in the present investigation was the stimulatory effect of morphine on pancreatic calcium output. As protein secretion was depressed by morphine, we expected a depression of calcium secretion, which is known to reach the pancreatic juice in association with protein. ${ }^{19-21}$ The reason for this apparent discrepancy is not clear. There is evidence showing that, in addition to the proteinbound fraction, a second protein-independent calcium fraction exists in pancreatic juice. ${ }^{19} 2122$ It has been suggested that this second fraction of calcium enters the juice by diffusion from the interstitial space ${ }^{19}{ }^{23}$ or by the mechanism responsible for electrolyte secretion. ${ }^{21}{ }^{22}$ It is therefore possible that morphine increased this proteinindependent fraction of pancreatic juice calcium, perhaps by the same mechanism involved in augmentation of water and bicarbonate secretion. 
In conclusion, this study demonstrates that human pancreatic secretion is strongly influenced by morphine. The prevention of the effects of morphine by naloxone suggests that separate opiate receptors might be involved in these effects. The recent discovery in the human pancreas of endogenous peptides with morphine-like activity ${ }^{24}$ adds some speculative interest to the present findings.

The authors wish to thank $\mathrm{Dr} \mathrm{T}$ E Solomon for critical review of the manuscript.

\section{References}

1 Bowman WC, Rand MJ. Textbook of pharmacology. Oxford: Blackwell, 1980.

2 Gilman AG, Goodman LS, Gilman A. The pharmacological basis of therapeutics. New York: MacMillan, 1980.

3 Gullo L, Costa PL, Fontana G, Tessari R, Serra D, Labd G. Effect of adrenocorticotropic hormone on pure exocrine pancreatic secretion in man. Gastroenterology 1977; 73: 762-4.

4 Gullo L, Costa PL, Tessari R, Fontana G. Cortisol and pancreatic secretion. Observations on pure pancreatic juice. Scand J Gastroenterol 1980; 15: 45-7.

5 Leger L, Brehant J. Chirurgie du pancreas. Paris: Masson, 1956.

6 Tournut R, White TT. Water, electrolyte and protein secretions of the human exocrine pancreas in the early post-operative period. Surg Gynecol Obstet 1972; 135: 17-21.

7 Konturek SJ, Tasler J, Cieszkowski M, Jaworek J, Coy DH, Schally AV. Inhibition of pancreatic secretion by enkephalin and morphine in dogs. Gastroenterology 1978; 74: 851-5.

8 Van Slyke DD, Neil JM. The determination of gases in blood and other solutions by vacuum extracting and manometric measurement. I. J Biol Chem 1924; 61: 523-73.

9 Figarella C, Ribeiro T. The assay of human pancreatic phospholipase $\mathbf{A}$ in pancreatic juice and duodenal contents. Scand J Gastroenterol 1971; 6: 133-7.
10 Miller JM, Wiper TB. Physiologic observations on patients with external pancreatic fistula. Ann Surg 1944; 120: 852-72.

11 Lagerlof HO. The influence of morphine hydrochloride on the pancreatic and biliary secretion in man. Acta Physiol Scand 1947; 13: 306-9.

12 Paton WDM. The action of morphine and related substances on contraction and on acetylcholine output of coaxially stimulated guinea-pig ileum. $\mathrm{Br} J$ Pharmacol 1957; 12: 118-28.

13 Jhamandas K, Pinsky C, Phillis JW. Effects of morphine and its antagonists on release of cerebral cortical acetylcholine. Nature 1970; 228: 176-7.

14 Sing M, Webster PD. Neurohormonal control of pancreatic secretion. Gastroenterology 1978; 74: 294309.

15 Oldendorf WH, Hyman S, Braun L, Oldendorf SZ. Blood-brain barrier: penetration of morphine, codeine, heroin, and methadone after carotid injection. Science 1972; 178: 984-6.

16 Tolis G, Hickey J, Guyda H. Effects of morphine on serum growth hormone, cortisol, prolactin and thyroid stimulating hormone in man. J Clin Endocrinol Metab 1975; 41: 797-800.

17 Feldman M, Walsh JH, Taylor IL. Effect of naloxone and morphine on gastric acid secretion and on serum gastrin and pancreatic polypeptide concentrations in humans. Gastroenterology 1980; 79: 294-8.

18 Ipp E, Dobbs R, Unger RH. Morphine and betaendorphin influence the secretion of the endocrine pancreas. Nature 1978; 276: 190-1.

19 Goebell H, Steffen C, Bode C. Stimulatory effect of pancreozymin-cholecystokinin on calcium secretion in pancreatic juice of dogs. Gut 1972; 13: 477-82.

20 Case RM. Calcium and gastrointestinal secretion. Digestion 1973; 8: 269-88.

21 Ceccarelli B, Clemente F, Meldolesi J. Secretion of calcium in pancreatic juice. $J$ Physiol 1975; 245: 617-38.

22 Argent BE, Case RM, Scratcherd T. Amylase secretion by the perfused cat pancreas in relation to the secretion of calcium and other electrolytes and as influenced by the external ionic environment. J Physiol 1973; 230: 575-93.

23 Makhlouf GM, Blum AL. An assessment of models for pancreatic secretion. Gastroenterology 1970; 59: 896908.

24 Polak JM, Sullivan SN, Bloom SR, Facer P, Pearse AGE. Enkephalin-like immunoreactivity in the human gastrointestinal tract. Lancet 1977; 1: 972-4. 